\section{Effect of Reciprocating Systems and Working Lengths on Apical Microcrack Development: A micro-CT Study}

Bruna Paloma de Oliveira ${ }^{1}$, Andréa Cruz Câmara ${ }^{1}$, Daniel Amancio Duarte², Richard John Heck ${ }^{3}$, Antonio Celso Dantas Antonino ${ }^{2}$, Carlos Menezes Aguiar ${ }^{1}$
'Department of Prosthodontics and Oral and Maxillofacial Surgery, Dental School, UFPE - Universidade Federal de Pernambuco, Recife, PE, Brazil ${ }^{2}$ Department of Nuclear Energy, UFPE - Universidade Federal de Pernambuco, Recife, PE, Brazil ${ }^{3}$ Department of Land Resource Science, University of Guelph, Guelph, Canada

Correspondence: Bruna Paloma de Oliveira, Av. Prof. Moraes Rego s/n, Cidade Universitária, 50670-901 Recife, PE Brasil. Tel: +55-81-99285-3170. e-mail:

\author{
bruna_paloma@msn.com
}

\begin{abstract}
The objective of this study was to evaluate the effect of root canal preparation with single-file reciprocating systems at different working lengths on the development of apical microcracks using micro-computed tomographic (micro-CT) imaging. Forty extracted human mandibular incisors were randomly assigned to 4 groups $(n=10)$ according to the systems and working length used to prepare the root canals: Group A - WaveOne Gold at apical foramen (AF), Group B - WaveOne Gold $1 \mathrm{~mm}$ short of the AF (AF-1 mm), Group $C$ - Unicone (AF) and Group D - Unicone (AF-1 mm). Micro-CT scanning was performed before and after root canal preparation at an isotropic resolution of $14 \mu \mathrm{m}$. Then, three examiners assessed the cross-sectional images generated to detect microcracks in the apical portion of the roots. Apical microcracks were visualized in $3,1,1$, and 3 specimens in groups $A, B, C$, and $D$, respectively. All these microcracks observed after root canal preparation already existed prior to instrumentation, and no new apical microcrack was detected. For all groups, the number of slices presenting microcracks after root canal preparation was the same as before canal preparation. Root canal preparation with WaveOne Gold and Unicone, regardless of the working length, was not associated with apical microcrack formation.
\end{abstract}

\section{Introduction}

In 2008, a new root canal preparation technique with only one nickel-titanium instrument in a reciprocating motion was proposed by Yared (1). Since then a number of reciprocating instruments have been introduced. WaveOne Gold (Dentsply Maillefer, Ballaigues, Switzerland) and Unicone (Medin, Nové Město na Moravě, Czech Republic) are examples of recently launched reciprocating systems that operate under the concept of preparing root canals with only one instrument. Although the use of a single file simplifies instrumentation and provides a safe and effective means of root canal shaping $(1,2)$, research data have been inconsistent about the biomechanical impact on root dentin generated by reciprocating instruments.

It has been speculated that the use of a single largetapered file, rather than a sequence of instruments, for root canal preparation result in a higher level of stress concentrations in root canal walls and consequently in the formation of more dentinal defects (3). On the other hand, the continuous release of the file when it is engaged within the root canal, promoted by the reciprocating motion, has been suggested to reduce the stresses acting on the dentin, resulting in the production of significantly fewer cracks than continuous rotation instruments (4). Additionally, studies on the development of dentinal defects have speculated that variations in the working length may have a significant effect on incidence of apical cracks (5).

However, most of these assertions have been based on root sectioning studies, which in order to investigate fracture lines after the biomechanical preparation of the root canals, have used a saw to section the roots, and the resulting slices were inspected through a stereomicroscope (6). This sectioning method has a substantial drawback that may induce false-positive results, given that dentinal cracks may occur because of the tooth sectioning procedure, (7). In addition, defects previously present in root dentin may not be detected before root canal instrumentation (8).

Micro-computed tomography (micro-CT) has allowed new perspectives for endodontic research (9), especially to the studies on the factors related to the induction of dentinal microcracks. This technology makes it possible to investigate the presence of dentinal defects with a detailed resolution before and after canal preparation without sectioning the specimens (10-14).

Up to now, no study has used nondestructive methodology to assess the impact of instrumentation with WaveOne Gold and Unicone at different working lengths on microcrack formation. Therefore, the aim of the present study was to evaluate the effect of root canal preparation with WaveOne Gold and Unicone when working short and at the apical foramen (AF) on the development of apical 
microcracks using micro-CT scanning.

\section{Material and Methods}

\section{Sample Selection and Preparation}

After approval of the Ethical Committee of the Federal University of Pernambuco (no. 1.697.309), freshly extracted human mandibular incisors were obtained. The specimens were extracted for reasons unrelated to this study and stored in purified filtered water until use. Radiographs were taken from the mesiodistal and buccolingual planes. Then, the root surfaces were inspected under a stereomicroscope (Stemi 2000-C, Zeiss, São Paulo, SP, Brazil) with 12X magnification. Lower incisors free of external dentinal defects, endodontic treatment, root caries and internal/ external resorption, as well as presenting mature apices and single straight root canals $\left(<5^{\circ}\right)(15)$ were selected. Subsequently, the teeth were decoronated under water cooling with a low-speed saw (Isomet; Buehler Ltd, Lake Bluff, IL, USA) approximately $13 \mathrm{~mm}$ from the apex. Teeth not patent to the canal length with a size \#10 K-file (Dentsply Maillefer) were discarded. Meeting these criteria, a total of 40 specimens were selected.

Samples were then imaged using a micro-CT scanner (XTH225ST, Nikon, Japan) with exposure parameters set at $14 \mu \mathrm{m}$ isotropic resolution, $70 \mathrm{kV}$ voltage and $114 \mu \mathrm{A}$ current. X-rays were filtered with a 1-mm-thick aluminum filter. To reduce ring artifacts and minimize the beam hardening effect, an air calibration of the detector was carried out before the scans. Images of each specimen were reconstructed with CT Pro 3D v.XT3.1.3 software (Nikon Metrology NV). VGStudio MAX ${ }^{\circledR}$ v.2.2 software was subsequently used to smooth images with a Gaussian filtering application, and provide cross-sections of the internal structure of the roots.

\section{Root Canal Preparation}

The distance between the reference plane and $\mathrm{AF}$ of specimens was determined by inserting a size \#10 K-file into the canal until its tip was just visible at the AF. The root surfaces were coated with a thin film of silicone-based impression material and embedded in autopolymerizing acrylic resin to simulate the periodontal ligament (16).

The teeth were numbered and randomly allocated into 4 experimental groups $(n=10)$ according to the systems and working lengths used for the root canal preparation. The following reciprocating files were tested: WaveOne Gold and Unicone. The working lengths analyzed were: instrumentation finished at the $\mathrm{AF}(\mathrm{AF})$ and instrumentation finished $1 \mathrm{~mm}$ short of the AF (AF-1 mm). As follow: Group A: WaveOne Gold (AF); Group B: WaveOne Gold (AF-1 mm); Group C: Unicone (AF); Group D: Unicone (AF-1 mm).

The glide path was performed using a size \#15 K-file
(Dentsply Maillefer) up to the working length. The WaveOne Gold Primary (25/0.07) and Unicone (25/0.06) instruments were used in a slow in-and-out pecking motion of approximately $3 \mathrm{~mm}$ in amplitude until the working length was reached. After 3 pecking motions, the flutes of the instruments were cleaned and the canals were irrigated. A total of $15 \mathrm{~mL} 1 \%$ sodium hypochlorite was used per canal. Final irrigation was performed using $5 \mathrm{~mL}$ distilled water.

Each instrument was used in 4 canals and operated with a low-torque motor (X-Smart Plus, Dentsply Maillefer) set at the WaveOne program. A single operator completed all preparations. Composite resin was used to fix the rubber stoppers and avoid their displacement during instrumentation.

After the root canal preparations, the specimens $(n=40)$ were imaged again with micro-CT (post-instrumentation scan) using the same parameters applied in the preinstrumentation scan.

\section{Microcracks Evaluation}

Three examiners blindly evaluated the micro-CT cross-sectional images obtained before and after instrumentations $(n=22,880)$ to identify the presence of any dentinal microcrack along the $4 \mathrm{~mm}$ apical portion of the roots. The examiners were previously calibrated endodontic specialists. The calibration consisted of written and verbal instructions about micro-CT image interpretation with examples of micro-CT slices generated from cracked roots that were not included in the study sample. A microcrack was defined as any incomplete crack (line extending from the canal wall into the dentin without reaching the outer surface of the root), complete crack (line extending from the root canal wall to the outer surface), or craze line (other lines that did not reach any surface of the root or extend from the outer surface into the dentin but did not reach the canal wall) observed in the root dentin (3).

If a post-instrumentation image exhibited a microcrack line, the pre-instrumentation corresponding cross-section image also was inspected to check the pre-existence of a dentinal defect (10). The image assessments were repeated after an interval of 4 weeks. In case of discrepancy in the observations, the slices were examined at the same time by the three examiners until reaching an agreement.

\section{Results}

Overall, $8(20 \%)$ specimens presented some dentinal defect. Apical microcracks were detected in $3(30 \%), 1$ $(10 \%), 1(10 \%)$ and $3(30 \%)$ specimens in groups $A$ (WaveOne Gold - AF), B (WaveOne Gold - AF-1mm), C (Unicone $A F$ ), and $D$ (Unicone - AF-1mm), respectively. All these microcracks detected after root canal preparation were already present before instrumentation (Fig. 1). Thereby, 
independent of the system or working length tested, no new apical microcrack was generated.

Microcracks were detected in $1058(4.62 \%)$ crosssection images, from a total of 22,880 slices obtained. Table 1 summarizes the distribution of slices presenting

Table 1. Distribution of slices $(n=22,880)$ presenting apical microcracks according to system and working length

\begin{tabular}{lccc}
\hline \multirow{2}{*}{ System } & \multicolumn{2}{c}{ Working length } & \multirow{2}{*}{ Total (\%) } \\
\cline { 2 - 3 } & $\mathrm{AF}(\%)$ & $\mathrm{AF}-1 \mathrm{~mm}(\%)$ & \\
\hline $\begin{array}{l}\text { WaveOne } \\
\text { Gold }\end{array}$ & $262(1.15)$ & $362(1.58)$ & $624(2.73)$ \\
Unicone & $180(0.79)$ & $254(1.11)$ & $434(1.90)$ \\
Total & $442(1.93)$ & $616(2.69)$ & $1058(4.62)$ \\
\hline
\end{tabular}
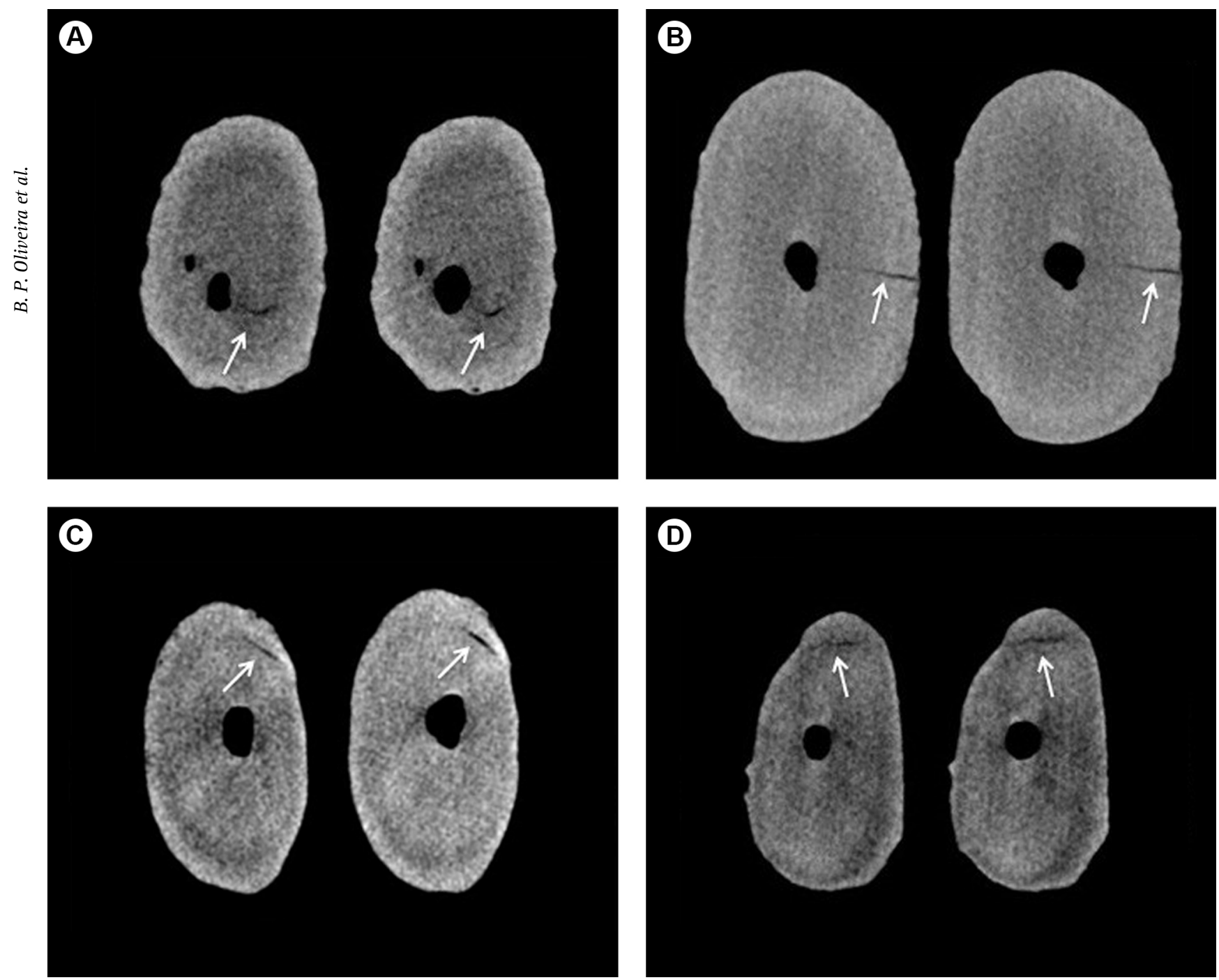

Figure 1. Representative micro-CT cross-sectional images obtained from 4 mandibular incisors, before and after root canal preparation with: (A) Wave0ne Gold when instrumentation was terminated at apical foramen (AF); (B) WaveOne Gold when instrumentation was terminated 1 mm short of the apical foramen (AF-1 mm); (C) Unicone when instrumentation was terminated at AF; (D) Unicone when instrumentation was terminated at AF-1 mm. Crack lines are indicated by the arrows. 
instruments produced dentinal defects in $46.6 \%$ of the specimens at the apical level.

Most of these studies have used the root sectioning method by which, after root canal preparation, the specimens are sectioned at various levels from the apex, and the resulting slices are observed through a stereomicroscope. This methodology seemed to be a safe way for cutting the roots because its negative control groups, composed of uninstrumented teeth, were devoid of cracks after the sectioning procedures (6). However, a recent study (7) showed that slices of unprepared roots had defects that could not be visualized without LED transillumination, putting into question the reliability of the aforementioned method.

The need of employ a more reproducible method to assess dentinal microcracks led the authors to use micro-CT scanning in the present investigation. This highly accurate technology provides high-resolution images in all three dimensions without sectioning the samples, allowing the assessment of dentinal defects before and after root canal shaping on the same tooth (10). Under this micro-CT methodology, the current study revealed that no microcrack was attributed to the instrumentation with the tested reciprocating systems. This result are in agreement with De-Deus et al. (10) and Lim et al. (13) who also showed a lack of relationship between microcrack formation and biomechanical preparation with reciprocating instruments by using micro-CT analysis.

Factors such as trauma suffered by the tooth donor, extraction forces, and storage procedures have been suggested as responsible for dentinal cracks or craze lines present in some extracted teeth (20). Therefore, pre-existing dentinal defects should be expected in samples of crack studies. As performed in the root sectioning studies, the specimens preselected for the present study were evaluated through a stereomicroscope to discard those exhibiting external defects. Nevertheless, the pre-instrumentation images revealed the presence of apical microcracks in $20 \%$ of the samples used here. This finding agrees with earlier micro-CT studies $(10-12,14)$, which also verified a total amount of dentinal microcracks ranging from 16.7\%$34.6 \%$ in uninstrumented roots. Thus, merely an evaluation of the root surfaces under magnification is not sufficient to detect all of the pre-existing dentinal defects, which in addition to those produced by the sectioning procedure might induce false-positive results when a destructive methodology is employed.

A dentinal microcrack may gradually propagate to a vertical root fracture leading to tooth extraction (21). In the present study, in which the longitudinal length of the microcracks were analyzed before and after root canal preparation through micro-CT analysis, instrumentation procedures were not related to the longitudinal propagation of the pre-existing microcracks. This result presents a relevance because teeth presenting dentinal defects before canal preparation are not an uncommon event due to circumstances such as trauma, masticatory function and parafunctions occurred during the patient's life (22).

It has been stated that instrumentation to AF increases the risk of apical dentinal defects (5). The results of our study demonstrated that variations in the working length did not influence microcrack development, even when the instrumentation was terminated at AF. This is an important finding for clinicians considering that preparation to a level as close to the AF as possible has been suggested as a way to optimizing root canal disinfection, especially in cases of periradicular lesions, where the most apical portion of the canal may harbor a niche for microbial colonization (23).

A crucial point regarding the studies on the incidence of dentinal microcracks is the subjectivity in the image analysis, which can influence the results. In the present study some cares were taken in order to guarantee an unbiased evaluation and diminish limitations of a subjective analysis. The micro-CT cross-sectional images were analyzed by three pre-calibrated experienced endodontic specialists, blind to the experimental groups. It is important to point out that the operator who completed the experimental procedures did not take part in the microcrack evaluations. And to avoid that the examiners were aware of the presence of a microcrack in the pre-instrumentation image, postinstrumentation images were analyzed first.

Although in the present investigation the biomechanical preparation with reciprocating systems not have been related to the development of microcracks; it is important to point out that, besides removal of dentin, several other factors such as curvature of the root $(12,24)$, canal size and shape (24), presence of natural periodontal ligament (20), and the age of the tooth (25) might interact together in influencing fracture susceptibility. Therefore, further microCT studies are necessary to provide a better understanding of factors related to dentinal microcracks, and consequently allow a better prevention and management of this worrisome entity.

Under the conditions tested and within the limitations of this in vitro study, it could be concluded that the instrumentation of root canals with WaveOne Gold and Unicone systems, regardless of the working length, was not associated with apical microcracks formation.

\section{Resumo}

0 objetivo deste estudo foi avaliar o efeito da instrumentação de canais radiculares utilizando sistemas reciprocantes de lima única em diferentes comprimentos de trabalho sobre o desenvolvimento de microfissuras apicais utilizando imagens de microtomografia computadorizada (microCT). Quarenta incisivos inferiores humanos extraídos foram distribuidos 
aleatoriamente em 4 grupos $(n=10)$ de acordo com os sistemas e comprimentos de trabalho utilizados para preparar os canais radiculares: Grupo A - WaveOne Gold no forame apical (FA), Grupo B - WaveOne Gold 1 mm aquém do FA (FA-1 mm), Grupo C - Unicone (FA) e grupo D - Unicone (FA-1 mm). Escaneamentos de micro-CT foram realizados antes e após o preparo dos canais a uma resolução isotrópica de $14 \mu \mathrm{m}$. Em seguida, três examinadores avaliaram as imagens de secção transversal geradas para detectar microfissuras na porção apical das raizes. Microfissuras apicais foram visualizadas em 3, 1, 1 e 3 espécimes nos grupos A, B, C e $D$, respectivamente. Todas essas microfissuras observadas após o preparo dos canais radiculares já existiam antes da instrumentação e não foi detectada nenhuma nova microfissura apical. Para todos os grupos, o número de cortes apresentando microfissuras após o preparo dos canais radiculares foi o mesmo verificado antes do preparo dos canais. A instrumentação de canais radiculares utilizando WaveOne Gold e Unicone, independentemente do comprimento de trabalho, não foi associada à formação de microfissuras apicais.

\section{Acknowledgements}

This study was supported by the Brazilian agency CAPES (Coordenação de Aperfeiçoamento de Pessoal de Nivel Superior). We acknowledge the X-ray Computed Tomography Laboratory (LTC_RX) of Nuclear Energy Department of Federal University of Pernambuco for the micro-CT scans.

\section{References}

1. Yared G. Canal preparation using only one NiTi rotary instrument: preliminary observations. Int Endod J 2008;41:339-344.

2. Saleh AM, Vakili Gilani P, Tavanafar S, Schäfer E. Shaping ability of 4 different single-file systems in simulated S-shaped canals. J Endod 2015;41:548-552.

3. Bürklein S, Tsotsis P, Schäfer E. Incidence of dentinal defects after root canal preparation: reciprocating versus rotary instrumentation. J Endod 2013;39:501-504.

4. Kansal R, Rajput A, Talwar S, Roongta R, Verma M. Assessment of dentinal damage during canal preparation using reciprocating and rotary files. J Endod 2014;40:1443-1446.

5. Liu R, Kaiwar A, Shemesh H, Wesselink PR, Hou B, Wu MK. Incidence of apical root cracks and apical dentinal detachments after canal preparation with hand and rotary files at different instrumentation lengths. J Endod 2013;39:129-132.

6. Bier CA, Shemesh H, Tanomaru-Filho M, Wesselink PR, Wu MK. The ability of different nickel-titanium rotary instruments to induce dentinal damage during canal preparation. J Endod 2009;35:236-238.

7. Coelho MS, Card SJ, Tawil PZ. Visualization enhancement of dentinal defects by using light-emitting diode transillumination. J Endod 2016;42:1110-1113.

8. Coelho MS, Card SJ, Tawil PZ. Light-emitting diode assessment of dentinal defects after root canal preparation with Profile, TRUShape, and WaveOne Gold systems. J Endod 2016;42:1393-1296.

9. Araújo VL, Souza-Gabriel AE, Cruz Filho AM, Pécora JD, Silva RG. Volume of sealer in the apical region of teeth filled by different techniques: a micro-CT analysis. Braz Oral Res 2016;30.

10. De-Deus G, Silva EJ, Marins J, Souza E, Neves Ade A, Gonçalves Belladonna $F$, et al.. Lack of causal relationship between dentinal microcracks and root canal preparation with reciprocation systems. $J$ Endod 2014;40:1447-1450.

11. De-Deus G, Belladonna FG, Souza EM, Silva EJ, Neves Ade A, Alves H, et al.. Micro-computed tomographic assessment on the effect of ProTaper Next and Twisted File Adaptive systems on dentinal cracks. J Endod 2015:41:1116-1119.

12. Ceyhanli KT, Erdilek N, Tatar I, Celik D. Comparison of ProTaper, RaCe and Safesider instruments in the induction of dentinal microcracks: a micro-CT study. Int Endod J 2016;49:684-689.

13. Lim $\mathrm{H}, \mathrm{Li} F \mathrm{FC}$, Friedman $\mathrm{S}$, Kishen A. residual microstrain in root dentin after canal instrumentation measured with digital moire interferometry. J Endod 2016;42:1397-1402.

14. De-Deus G, Belladonna FG, Marins JR, Silva EJ, Neves AA, Souza EM, et al.. On the causality between dentinal defects and root canal preparation: a micro-CT assessment. Braz Dent J 2016;27:664-669.

15. Schneider SW. A comparison of canal preparations in straight and curved root canals. Oral Surg Oral Med Oral Pathol 1971;32:271-275.

16. Liu R, Hou BX, Wesselink PR, Wu MK, Shemesh H. The incidence of root microcracks caused by 3 different single-file systems versus the ProTaper system. J Endod 2013;39:1054-1056.

17. Topçuoğlu HS, Düzgün $S$, Akpek F, Topçuoğlu G. Effect of glide path and apical preparation size on the incidence of apical crack during the canal preparation using Reciproc, WaveOne, and ProTaper Next systems in curved root canals: A stereomicroscope study. Scanning 2016;38:585590.

18. Helvacioglu-Yigit D, Aydemir S, Yilmaz A. Evaluation of dentinal defect formation after root canal preparation with two reciprocating systems and hand instruments: an in vitro study. Biotechnol Biotechnol Equip 2015;29:368-373.

19. Ashwinkumar V, Krithikadatta J, Surendran S, Velmurugan N. Effect of reciprocating file motion on microcrack formation in root canals: an SEM study. Int Endod J 2014;47:622-627.

20. Arias $\mathrm{A}$, Lee $\mathrm{YH}$, Peters $\mathrm{Cl}$, Gluskin $\mathrm{AH}$, Peters OA. Comparison of 2 canal preparation techniques in the induction of microcracks: a pilot study with cadaver mandibles. J Endod 2014:40:982-985.

21. Wilcox LR, Roskelley $C$, Sutton T. The relationship of root canal enlargement to finger-spreader induced vertical root fracture. J Endod 1997;23:533-534.

22. Ratcliff S, Becker IM, Quinn L. Type and incidence of cracks in posterior teeth. J Prosthet Dent 2001;86:168-172.

23. Wu MK, Wesselink PR, Walton RE. Apical terminus location of root canal treatment procedures. Oral Surg Oral Med Oral Pathol Oral Radiol Endod 2000;89:99-103.

24. Sathorn C, Palamara JE, Palamara D, Messer HH. Effect of root canal size and external root surface morphology on fracture susceptibility and pattern: a finite element analysis. J Endod 2005;31:288-292.

25. Koester KJ, Ager JW 3rd, Ritchie RO. The effect of aging on crackgrowth resistance and toughening mechanisms in human dentin. Biomaterials 2008;29:1318-1328. 